\title{
Scale-Up Preparation and Characterization of Collagen/Sodium Alginate Blend Films
}

\author{
Zhe Wang, Shuaifeng Hu, and Huaiyu Wang \\ Center for Biomedical Materials and Interfaces, Shenzhen Institutes of Advanced Technology, Chinese Academy of Sciences, \\ Shenzhen 518055, China \\ Correspondence should be addressed to Zhe Wang; zhe.wang@siat.ac.cn
}

Received 31 May 2017; Revised 16 August 2017; Accepted 11 September 2017; Published 14 November 2017

Academic Editor: Quan V. Vuong

Copyright (C) 2017 Zhe Wang et al. This is an open access article distributed under the Creative Commons Attribution License, which permits unrestricted use, distribution, and reproduction in any medium, provided the original work is properly cited.

In an effort to produce scale-up of edible films, collagen-based films including different amounts of sodium alginate (CS) were prepared by casting method. Films were characterized based on their rheological, thermal, and mechanical properties, water vapor permeability (WVP), and oxygen permeability (OP). The microstructures were also evaluated by scanning electron microscopy (SEM), atomic force microscopy (AFM), and Fourier transform-infrared spectroscopy (FTIR). Furthermore, the addition of sodium alginate effectively improved the viscosity and thermal stability, significantly increased TS, and decreased $E$ and WVP $(P<0.05)$, but with no obvious effect on OP $(P>0.05)$. SEM and AFM showed homogeneous matrix, with no signs of phase separation in the blends. Overall, films (CS2) produced using collagen $(\mathrm{g})$ : sodium alginate $(\mathrm{g})=10: 2$ showed suitable rheological property (apparent viscosity was $4.87 \mathrm{~m} \mathrm{~Pa} \mathrm{~s}^{-1}$ ) and better TS (26.49 Mpa), E (64.98\%), WVP $\left(1.79 \times 10^{-10} \mathrm{~g} \cdot \mathrm{cm}^{-1} \cdot \mathrm{s}^{-1} \cdot \mathrm{Pa}^{-1}\right)$, and OP $(3.77 \times$ $\left.10^{-5} \mathrm{~cm}^{3} \cdot \mathrm{m}^{-2} \cdot \mathrm{d}^{-1} \cdot \mathrm{Pa}^{-1}\right)$.

\section{Introduction}

Food packaging is concerned with the preservation and protection of all types of foods, particularly from oxidative and microbial spoilage, and also extending their shelf-life characteristics. Increased use of synthetic packaging films has led to serious ecological problems due to their total nonbiodegradability $[1,2]$. Thereby, the use of proper packaging materials and methods to minimize food losses and provide safe and wholesome food products had always been the main interest [3-7].

Indeed, more and more attention has been paid to develop edible films in order to improve food safety and shelf-life [810]. Edible films need to possess the appropriate mechanical properties and barrier properties from initial product packing to final consumer usage [11, 12]. Meanwhile, the materials obtained from renewable natural sources that were used to prepare edible films mainly include proteins, lipids, polysaccharides, and their possible combinations $[13,14]$.

Among them, collagen is one of the renewable natural polymers, which could be widely used as an important industrial raw material [15]. It gained more significance, which offers real potential for applications in the food industry due to its physicochemical properties, short time biodegradability, and nontoxicity. Several authors have developed films or coatings based on collagen to preserve food in laboratory scale [15-20]. Nevertheless, since now, scale-up collagenbased films were not successfully produced, as would limit their application in food preservation field.

Alginate is a salt of alginic acid, a polymer of D-mannuronic acid and L-guluronic acid, and isolated from brown algae, used as an edible coating because of its unique colloidal properties and its ability to form strong gels or insoluble polymers upon reaction with multivalent metal cations, such as calcium $[6,21]$. As a stabilizer and a thickener, sodium alginate (SA), the main used form, is applied in various food products including drinks like chocolate milk and deserts like ice cream, jelly, sauces, and soups [22-25]. Particularly, edible films obtained from sodium alginates have obtained good mechanical characteristics and decreased oxygen transfer $[26,27]$.

Therefore, SA was added to collagen, in order to obtain a suitable rheological behavior for the collagen-based solution, paving the way to a large scale-up preparation for 
collagen-based films. More importantly, hydrogen and/or electrostatic interactions between carboxylate groups of SA and hydroxyl groups of collagen can occur, forming a more dense and compact matrix.

The objective of this paper was to prepare and evaluate the properties of different blending ratios of collagen-sodium alginate films in pilot scale. The films were characterized in terms of their rheological behavior, thermal stability, and mechanical properties, as well as their oxygen permeability and water vapor barrier property. Furthermore, their microstructure would be investigated by scanning electron microscopy, Fourier transform-infrared spectroscopy, and atomic force microscopy, respectively.

\section{Materials and Methods}

2.1. Materials. Fish skin collagen (MW: 2000-3000) was obtained from Shanghai Yuanye Bio-Technology Co., Ltd. Sodium alginate, glycerol, and glutaraldehyde were purchased from Sinopharm Chemical Reagent Co., Ltd. All of them were of analytical grade. Indeed, glutaraldehyde was added as a cross-linking agent, whereas glycerol was added as a plasticizer. The ultrapure water was used as a solvent for the solution preparation.

2.2. Film Preparation. Collagen/sodium alginate blend films were prepared using casting machine. Firstly, a collagen solution $(10 \%, \mathrm{w} / \mathrm{v})$ was prepared by dispersing collagen powder in distilled water at $65^{\circ} \mathrm{C}$ for 30 min under magnetic stirring. Subsequently, different weight of sodium alginate was added to collagen solution with mechanical stirring for $30 \mathrm{~min}$ at $60^{\circ} \mathrm{C}$, to obtain the mixed solutions with different ratio of collagen to sodium alginate $(10: 0,10: 1,10: 2,10: 3$, and $0: 2)$. Then glycerol $(20 \%$, based on the content of dried matter) was added as plasticizer, and glutaraldehyde $(0.5 \%$, $\mathrm{v} / \mathrm{v}$ ) was added as cross-linking agent. The details could be shown in Table 1.

The film-forming solutions were placed at vacuum condition for $60 \mathrm{~min}$ to remove bubbles at room temperature. Finally, the solution was cast onto the steel belt casting machine (TY7000, Zhaoqing Xintai Electromechanical Technology Co., Ltd.) at $60^{\circ} \mathrm{C}$ for $120 \mathrm{~min}$. As could be presented in Figure 1, the dried films were conditioned for $24 \mathrm{~h}$ at $50 \pm$ $5 \%$ relative humidity $(\mathrm{RH})$ and $25 \pm 1^{\circ} \mathrm{C}$ before determination.

2.3. Rheological Analysis. Flow properties of film-forming solutions are useful for identifying the most appropriate coating system and optimizing operating conditions [23, 28]. The rheological properties of collagen, SA, and their blended film-forming solutions were characterized by a rheometer (Anton Paar, MCR302, Austria) equipped with a parallelplate geometry $($ diameter $=25 \mathrm{~mm}$ and a gap $=0.2 \mathrm{~mm})$. All measurements were conducted at $25^{\circ} \mathrm{C}$. Before any measurement, samples rested for $2 \mathrm{~min}$, to allow the stresses induced during sample loading to relax.

Rheological characterization was carried out using stationary shear flow and oscillatory tests. The steady shear measurements (flow curves) were performed in an extended shear rate range ( 1 to $\left.200 \mathrm{~s}^{-1}\right)$.
According to the rheological analysis model [29], the flow $(n)$ and consistency indices $(K)$ were determined after adjusting the empirical data according to the Ostwald de Waele rheological model (a.k.a. the Power-Law Model):

$$
\tau=K D^{n}
$$

in which $\tau$ is the shear stress $(\mathrm{Pa}), K$ is the consistency index $\left(\mathrm{Pa} \mathrm{s}^{n}\right), D$ is shear rate, and $n$ is the flow-behavior index.

\subsection{Films Characterization}

2.4.1. Thickness. Thickness of the collagen-sodium alginate films was determined to the nearest $0.01 \mathrm{~mm}$ using a micrometer (Mitutoyo Manufacturing, Tokyo, Japan). Measurements were made in at least ten random locations on each film.

2.4.2. Mechanical Properties. Mechanical properties of the films, such as tensile strength (TS, MPa) and elongation at break $(E, \%)$, were determined at $25 \pm 1^{\circ} \mathrm{C}$ using a Testometric Machine (PARAM XLW (B) Auto Tensile Tester, Jinan, China) according to the ASTM standard method (D88201). Films were cut into rectangular strips that were $120 \mathrm{~mm}$ long and $15 \mathrm{~mm}$ wide. Stripes were equilibrated at $50 \% \mathrm{RH}$ and $25 \pm 1^{\circ} \mathrm{C}$ for $48 \mathrm{hrs}$ in a desiccator using saturated salt solutions of $\mathrm{MgCl}_{2}$ or $\mathrm{Mg}\left(\mathrm{NO}_{3}\right)_{2}$. The films were fixed with an initial grip separation of $80 \mathrm{~mm}$ and stretched at a cross-speed of $50 \mathrm{~mm} / \mathrm{min}$. A microcomputer was used to record the strength and elongation data. Tensile strength was calculated as the maximum load on the film before failure divided by the cross-sectional area of the specimen. Elongation was defined as the percent change in specimen length compared to the initial length between the grips. For each film, at least five replicate measurements were performed [30].

2.4.3. Water Vapor Permeability (WVP). Water vapor permeability tester (PERME TSY-TIL, Labthink Instruments Co., Ltd., Jinan, China) was used to determine the water vapor permeability (WVP, $\times 10^{-10} \mathrm{~g} \cdot \mathrm{cm}^{-1} \cdot \mathrm{s}^{-1} \cdot \mathrm{Pa}^{-1}$ ) of the films according to the ASTM standard method (D1653). Water vapor transmission rates were determined at $25 \pm$ $1^{\circ} \mathrm{C}$ and $50 \% \mathrm{RH}$ using saturated salt solutions of $\mathrm{MgCl}_{2}$ or $\mathrm{Mg}\left(\mathrm{NO}_{3}\right)_{2}$. The specimen was fixed to form a sealed environment with $2 / 3$ distilled water in the vessel. The water vapor transmission rate and transmission coefficient were determined by measuring the decreasing weight of distilled water over time. For each film, at least five replicates were performed [30].

2.4.4. Oxygen Permeability (OP). A gas permeability tester (GDP-C) (Brugger Feinmechanik GmbH, Germany) was utilized to test the oxygen permeability $\left(\mathrm{OP}, \times 10^{-5} \mathrm{~cm}^{3} \cdot \mathrm{m}^{-2}\right.$. $\left.\mathrm{d}^{-1} \cdot \mathrm{Pa}^{-1}\right)$ of the films according to the ASTM standard method (D3985-95). Oxygen transmission rates were determined at $25 \pm 1^{\circ} \mathrm{C}$ and $50 \% \mathrm{RH}$ using saturated salt solutions of $\mathrm{MgCl}_{2}$ or $\mathrm{Mg}\left(\mathrm{NO}_{3}\right)_{2}$. The sample was mounted in a gas transmission cell to form a sealed semibarrier between chambers. One chamber contained $\mathrm{O}_{2}$ at a specific high pressure and the other lower pressure chamber received the permeating $\mathrm{O}_{2}$. The lower pressure chamber was initially evacuated 


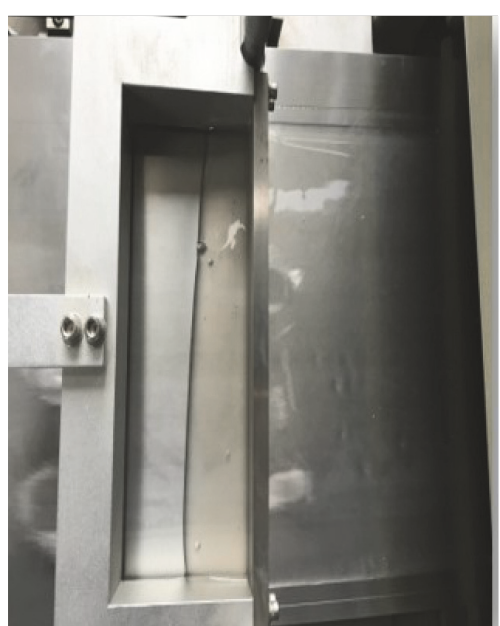

(a)

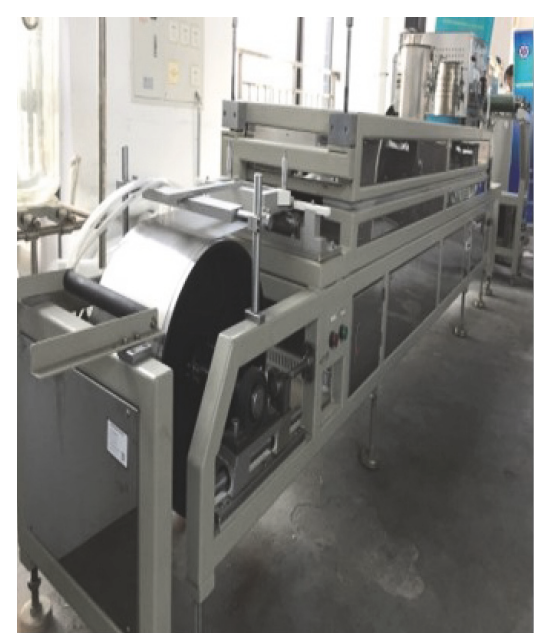

(b)

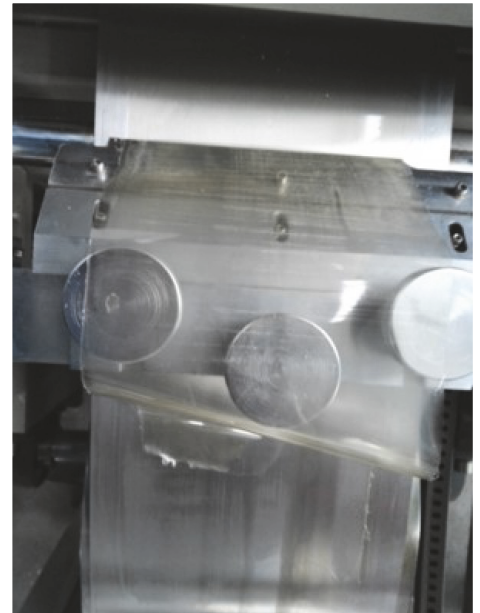

(c)

FIGURE 1: Casting machine used for films produced: (a) film-forming solution, (b) film drying, and (c) finished film.

and the transmission of the gas through the test specimen was indicated by an increase in pressure [30]. The $\mathrm{O}_{2}$ stream was set to $100 \mathrm{~mL} / \mathrm{min}$ and the oxygen transmission rate (OTR) was recorded. The OP was calculated by multiplying the OTR by the film thickness (FT) and then dividing by the partial pressure difference of oxygen $(\Delta P)$ as follows:

$$
\mathrm{OP}=\frac{\mathrm{OTR} \times \mathrm{FT}}{\Delta P} .
$$

For each film, at least five replicates were performed.

2.4.5. Thermal Properties. The thermal properties of samples were characterized as reported previously using differential scanning calorimeter (DSC-Q20, TA Instruments, USA). The samples $(3-4 \mathrm{mg})$ were heated with at $10^{\circ} \mathrm{C} / \mathrm{min}$ in the swept temperature from 10 to $300^{\circ} \mathrm{C}$ [19].

\subsection{Microstructure Characterization}

2.5.1. Fourier Transform-Infrared Spectroscopy (FTIR). FT-IR was recorded on a Nicolet 360 spectrometer (Thermo Nicolet Corporation, American) from 400 to $4000 \mathrm{~cm}^{-1}$ with the $\mathrm{KBr}$ method.

2.5.2. Scanning Electron Microscopy (SEM). The SEM images were acquired on a ZEISS SUPRA 55 (Carl Zeiss, Germany) field-emission scanning electron microscopy. For cross section analysis, samples were cryofractured after immersion in liquid nitrogen. The cryofractured section and film surface were analyzed without further preparation. The images were taken at random positions of the films.

2.5.3. Atomic Force Microscopy (AFM). The surface morphology of collagen-SA films was studied using a Multimode atomic force microscope (Bruker Multimode 8, Bruker, Germany) equipped with a Nanoscope V controller. The equipment was operated in noncontacting mode using etched silicon tip (nominal radius $8 \mathrm{~nm}$ and cantilever length of $230 \mu \mathrm{m}$ ) with a resonance frequency of about $267 \mathrm{kHz}$. AFM images were acquired in air at room temperature.

2.6. Statistical Analysis. All samples were analyzed in triplicate and one-way analysis of variance (ANOVA) was applied on the data followed by Duncan to distinguish the treatments at $P<0.05$. The statistical analyses were performed using SPSS version 17.0 (SPSS Inc., Chicago, IL, USA).

\section{Results and Discussion}

3.1. Rheological Analysis. The flow-behavior of film-forming solutions is an important property because it could affect the spread-ability, thickness, uniformity of the coating layer, the mechanical properties, and the application and processing design [28, 31]. Additionally, flow property modeling of filmforming solutions is useful technologically to identify the most appropriate coating system design and to optimize operating conditions [32].

The variation of viscosity and shear stress of collagenbased film-forming solution could be shown in Figure 2. Pure collagen solution showed Newtonian behavior between 0.1 and $200 \mathrm{~s}^{-1}$ shear rate range, whereas collagen/sodium alginate solution exhibited a shear-thinning behavior, confirming that the addition of SA enhanced the elastic behavior $(\mathrm{w} / \mathrm{v})$. As mentioned before, shear-thinning behavior is adequate for the production of films by tape casting.

As was presented in Table 1, flow-behavior index $(n)$ increased with increasing SA concentration; accordingly $K$ values primarily increased and then decreased. As expected, higher SA concentration led to a higher apparent viscosity. It suggests that SA was the prime factor affecting apparent viscosity. This may be attributed to the intramolecular interaction of SA which was destroyed; then new hydrogen bonds were formed between collagen and SA. Regardless of this, some researchers have demonstrated that high viscosity 


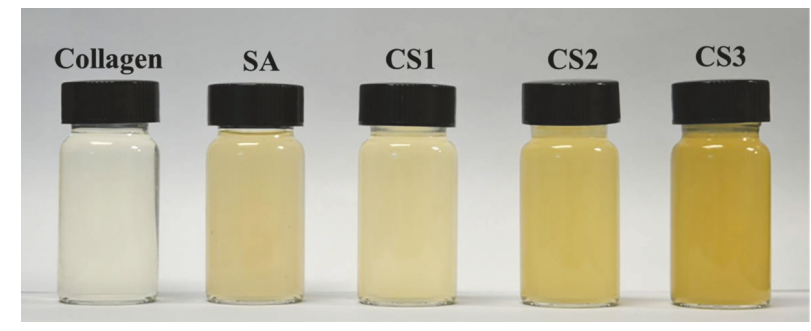

(a)

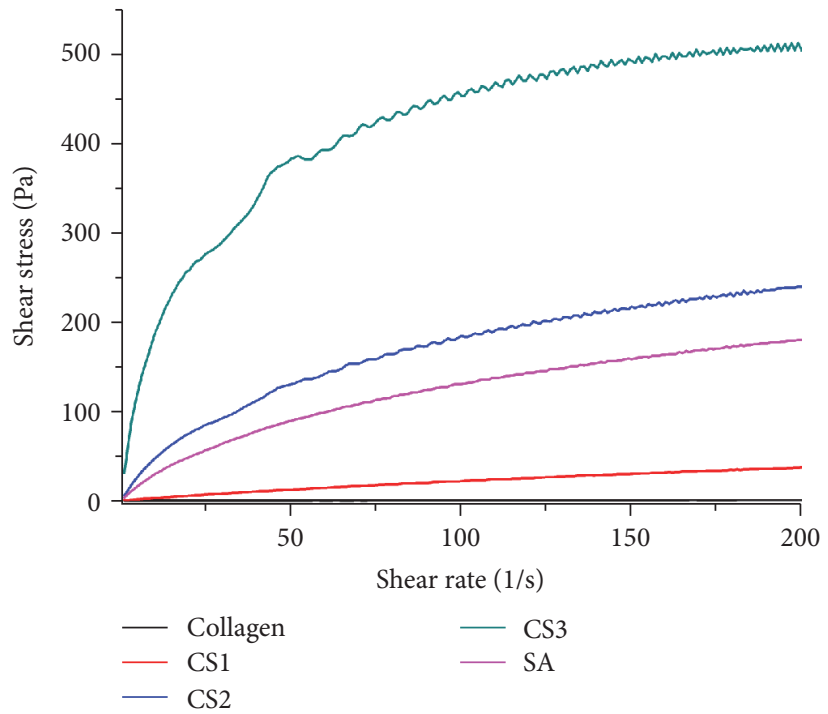

(b)

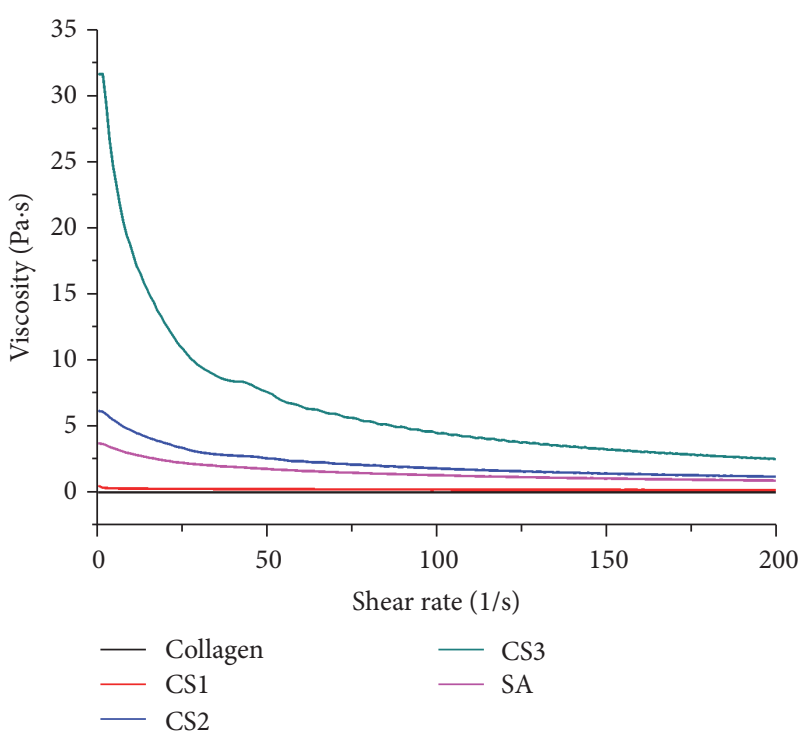

(c)

FIGURE 2: Characterization and rheological property evaluation for the films, (a) film-forming solution macrograph, (b) sheer stress versus shear rate, and (c) viscosity versus shear rate.

makes it difficult to disperse the ingredients and eliminate visible air bubbles during the preparation of liquid films $[23,32,33]$, leading to some discontinuities in the final films.

\subsection{Films Characterization}

3.2.1. Thickness. Indeed, all films were yellowish and flexible and could be easily handled. The surfaces of the films looked very smooth, without visible cracks or pores. Greater details regarding film appearances are described in Table 2.

Thickness of collagen films incorporated with SA at various concentrations is shown in Table 2 . Thickness of films incorporated with SA $(1-3 \%, \mathrm{w} / \mathrm{v})$ increased in comparison with the control. It ranged from 0.030 to $0.033 \mathrm{~mm}$. However, no significant difference in thickness was observed between films incorporated with SA $(P>0.05)$. Some authors also reported that the incorporation of SA had no effect on thickness of starch and pectin films [34, 35].

3.2.2. Mechanical Properties. Mechanical properties of biopolymer films are often presented in terms of tensile strength (TS) and elongation at break (E). TS accounts for film's mechanical resistance due to cohesion forces between chains, while $E$ measures its plasticity, which is capacity of a film to extend before breaking [36-38].
All test films showed significant $(P<0.05)$ differences in TS and $E$ (Table 2). Single collagen and SA films exhibited TS and $E$ value of 17.46 and $40.48 \mathrm{MPa}$ and $78.49 \%$ and $50.28 \%$, respectively. In general, polysaccharide-based films had better TS compared with protein-based films while protein-based films possessed greater $E$ than polysaccharidebased films [15, 17], agreeing well with the results of this study.

When the ratio of collagen to SA varied from $10: 0$ (pure collagen film) to $10: 3$ (CS3), TS was enhanced from 17.46 to $34.17 \mathrm{MPa}$, nearly more than double; however, $E$ decreased from $70.15 \%$ to $58.11 \%$. As suggested by [39], usually films with higher TS values show lower $E$ values, due to the structural nature of those attributes. This result was probably induced by a certain degree of cross-linking between the proteins of collagen and SA. As observed in the FTIR analysis, the hydrophobic interactions and hydrogen present bridges in proteins could be demonstrated (Section 3.3.1). It has been proved that lots of hydroxyl groups exist to allow formation of hydrogen bonds between side-by-side polymer chains, resulting in high TS of films made of protein or sodium alginate $[6,21,40]$. Moreover, it has been reported that the mechanical properties of films are greatly associated with distribution and of intra- and intermolecular interactions, depending on the arrangements, and orientation of polymer chains in the network [17]. According to the SEM analysis (Section 3.3.2), 
TABLE 1: Rheological properties of film-forming solutions: index of consistency $(K)$ and flow-behavior $(n)$ calculated by the Ostwald de Waele model. Apparent viscosity values at $10 \mathrm{~m} \mathrm{~S}^{-1}$ shear rate $(D)$.

\begin{tabular}{lccccc}
\hline Sample & $\begin{array}{c}\text { Mass ratios of } \\
\text { collagen to SA }\end{array}$ & $K$ & Parameters of Ostwald de Waele model & \multicolumn{2}{c}{$\begin{array}{c}\text { Apparent viscosity } \\
\left(\mathrm{m} \mathrm{Pa} \mathrm{s}^{-1}\right)\end{array}$} \\
\hline Collagen & $10: 0$ & 0.107 & 0.888 & 0.947 & $0.905 \mathrm{~m} \mathrm{~S}^{-1}$ \\
CS1 & $10: 1$ & 0.354 & 0.844 & 0.999 & 0.988 \\
CS2 & $10: 2$ & 1.083 & 0.582 & 0.964 & 4.87 \\
CS3 & $10: 3$ & 1.874 & 0.384 & 0.984 & 18.65 \\
SA & $0: 2$ & 0.995 & 0.538 & & 2.95 \\
\hline
\end{tabular}

TABLE 2: Collagen-sodium alginate films properties: tensile strength (TS), elongation at break (E), water vapor permeability (WVP), and oxygen permeability (OP).

\begin{tabular}{|c|c|c|c|c|c|}
\hline Films code & $\begin{array}{l}\text { Thickness } \\
(\mu \mathrm{m})\end{array}$ & $\begin{array}{c}\mathrm{TS} \\
(\mathrm{Mpa})\end{array}$ & $\begin{array}{c}E \\
(\%)\end{array}$ & $\begin{array}{c}\text { WVP } \\
\times 10^{-10} \mathrm{~g} \cdot \mathrm{cm}^{-1} \cdot \mathrm{s}^{-1} \cdot \mathrm{Pa}^{-1}\end{array}$ & $\begin{array}{c}\text { OP } \\
\times 10^{-5} \mathrm{~cm}^{3} \cdot \mathrm{m}^{-2} \cdot \mathrm{d}^{-1} \cdot \mathrm{Pa}^{-1}\end{array}$ \\
\hline Collagen & $30 \pm 2^{\mathrm{a}}$ & $17.46 \pm 1.13^{\mathrm{a}}$ & $78.49 \pm 3.59^{a}$ & $3.43 \pm 0.38^{\mathrm{a}}$ & $3.87 \pm 0.28^{\mathrm{a}}$ \\
\hline CS1 & $31 \pm 1^{\mathrm{a}}$ & $20.38 \pm 2.24^{\mathrm{b}}$ & $70.15 \pm 3.14^{\mathrm{b}}$ & $2.2 \pm 0.28^{\mathrm{b}}$ & $3.56 \pm 0.57^{\mathrm{ab}}$ \\
\hline $\mathrm{CS} 2$ & $32 \pm 2^{\mathrm{a}}$ & $26.49 \pm 2.67^{c}$ & $64.98 \pm 2.69^{c}$ & $1.7 \pm 0.26^{\mathrm{bc}}$ & $3.77 \pm 0.37^{\mathrm{a}}$ \\
\hline $\mathrm{CS} 3$ & $33 \pm 2^{\mathrm{a}}$ & $34.17 \pm 2.48^{\mathrm{d}}$ & $58.11 \pm 2.78^{\mathrm{d}}$ & $2.92 \pm 0.22^{\mathrm{ab}}$ & $3.85 \pm 0.42^{\mathrm{a}}$ \\
\hline SA & $11 \pm 1^{\mathrm{b}}$ & $40.48 \pm 1.49^{\mathrm{e}}$ & $50.28 \pm 1.38^{\mathrm{e}}$ & $2.74 \pm 0.35^{\mathrm{ab}}$ & $3.16 \pm 0.49^{b}$ \\
\hline
\end{tabular}

Values are expressed as mean \pm standard deviation. Different letters in the same column indicate significant differences $(P<0.05)$.

a uniformity appearance for the CS films is obtained, leading to a better mechanical property. Thus, SA could effectively improve the mechanical property of collagen films.

3.2.3. Water Vapor Permeability (WVP). Water vapor permeability (WVP) for the collagen, SA, and their blend films at relative humidity of $50 \%$ is shown in Table 2. Obtained values ranged from 1.79 to $3.43 \times 10^{-10} \mathrm{~g} \cdot \mathrm{cm}^{-1} \cdot \mathrm{s}^{-1} \cdot \mathrm{Pa}^{-1}$. As it is reported that collagen is a hydrophilic polymer which has hydroxyl groups, thus, the water vapor could easily permeate through the film. In this study, films with lower content of SA showed significantly lower values comparing to the pure collagen films. This was in accordance with the fact that WVP values for blend films produced from protein and polysaccharide mixtures were lower in comparison to the WVP values of those films formed from protein alone [41].

It is perhaps because more hydroxyl groups of SA could form more hydrogen bonds with water; thus water was trapped firmly in the polymer network. Similar results have been reported in the literature for feather keratin and SA blend films [21]. Further, it was discovered that SA could decrease the WVP probably through creating a tortuous pass for crossing water vapor through film, increasing the crystallinity of the biopolymer, or decreasing free hydrophilic groups $(\mathrm{OH}, \mathrm{NH})$ in biopolymer matrix [41, 42].

It was also worth noting that further increase in SA (CS3) caused an increase in the WVP of CS films. This may attribute to the fact that both collagen and SA owing to their hydrophilic nature attract water molecules and create mobile regions with larger interchain distances. Additionally, these hydrophilic SA compete with water at the active sites of the polymer matrix causing water clustering which also forms microcavities in the network structure $[43,44]$. The absorbed water molecules modify the film matrix, leading to a less dense structure where chain terminals are relatively more mobile, thus increasing water vapor transmission rate [45]. Therefore, the appropriate SA proportion could lead to a better barrier property for the blend films.

3.2.4. Oxygen Permeability (OP). Oxygen is responsible for many degradation processes in foods such as lipid oxidation, microorganism growth, enzymatic browning, and vitamin loss [46]. Consequently, oxygen permeability (OP) is a crucial property in food packaging and it could be used as an index to evaluate the ability to prohibit oxidation reaction [47].

Although the collagen films were hydrophilic and exhibited poor water vapor barrier properties, collagen-based films were hypothesized to be excellent barriers against oxygen, as examined in Table 2. Nevertheless, no significant differences $(P>0.05)$ were obtained between all the estimated values and no specific trends could be observed. The OP value of the pure collagen and SA film was 3.87 and $3.16 \times 10^{-5} \mathrm{~cm}^{3}$. $\mathrm{m}^{-2} \cdot \mathrm{d}^{-1} \cdot \mathrm{Pa}^{-1}$, indicating that the both films were good oxygen barrier. Similar results were obtained by Bonilla et al. [46]. It was also noted that films made from proteins and carbohydrates are excellent barriers to oxygen, because of their tightly packed, ordered hydrogen bonded network structure [48].

From this result, it appears that the addition of SA slightly changed OP of CS films, but with no obvious effect $(P>0.05)$. When the ratio of collagen to SA varied from $10: 1$ (CS1) to $10: 3$ (CS3), OP varied from 3.56 to $3.85 \times$ $10^{-5} \mathrm{~cm}^{3} \cdot \mathrm{m}^{-2} \cdot \mathrm{d}^{-1} \cdot \mathrm{Pa}^{-1}$. Among them, the OP for CS1 was found to be lowest, but further increase in SA concentration 


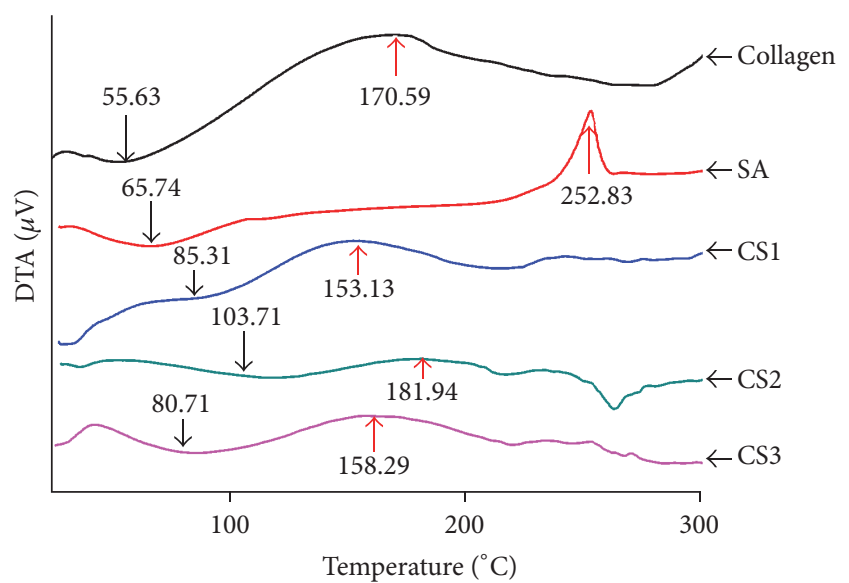

FIGURE 3: DSC thermograms of collagen, CS1, CS2, CS3, and SA films.

led to an increase in OP of CS films. Generally SA possess a film-forming ability, which leads to modest or very good oxygen barrier properties depending on the structure [11]. However, the result was not as good as expected in this study; $\mathrm{SA}$ added in the collagen could not decrease the OP values for the blend films.

3.2.5. Thermal Properties. Thermal properties of the samples were estimated using differential scanning calorimeter (DSC). It was known that DSC was a useful and rapid method to measure the interrelated thermodynamic profiles, and it was usually used to determine the temperature and enthalpy during endothermic or exothermic processes for an application in polymer materials [8]. The thermograms of DSC analysis and the related peak temperatures were given and illustrated in Figure 3.

It was reported that the first endothermic events were glass transition, followed by an endotherm associated with the melting of the ordered structures [20,49]. As observed in Figure 3, the $T_{g}$ value of the pure collagen film $\left(55.63^{\circ} \mathrm{C}\right)$ is inferior to $\operatorname{CS} 1\left(85.31^{\circ} \mathrm{C}\right), \operatorname{CS} 2\left(103.71^{\circ} \mathrm{C}\right)$, and CS3 $\left(80.71^{\circ} \mathrm{C}\right)$. It suggested that the thermal stability of the CS films has been enhanced, owing to the addition of SA. That may be explained by the increase of interactions provided by SA, stabilizing the collagen structure against unfolding and requiring a higher temperature to degrade collagen $[18,20]$. Nevertheless, the $T_{q}$ value for the CS films initially increased and then decreased, with the SA concentration increase. As reported, $T_{q}$ value of the collagen film is attributed to the hydrogen bonded networks and mediated by water molecules [50].

Oppositely, as observed, compared to the collagen film $\left(170.59^{\circ} \mathrm{C}\right), \operatorname{CS} 1\left(153.13^{\circ} \mathrm{C}\right)$ and $\operatorname{CS} 3\left(158.29^{\circ} \mathrm{C}\right)$ presented a decrease in $T_{c}$ value associated with thermal stability. The lower $T_{c}$ was related to the reduction in some weak intermolecular forces such as hydrogen bonds between water and the matrix. It could be explained that the hydrophobic feature was imparted into collagen and facilitated evaporation of water with SA added. Totally, the addition of SA effectively improved the thermal property for the CS blend films.

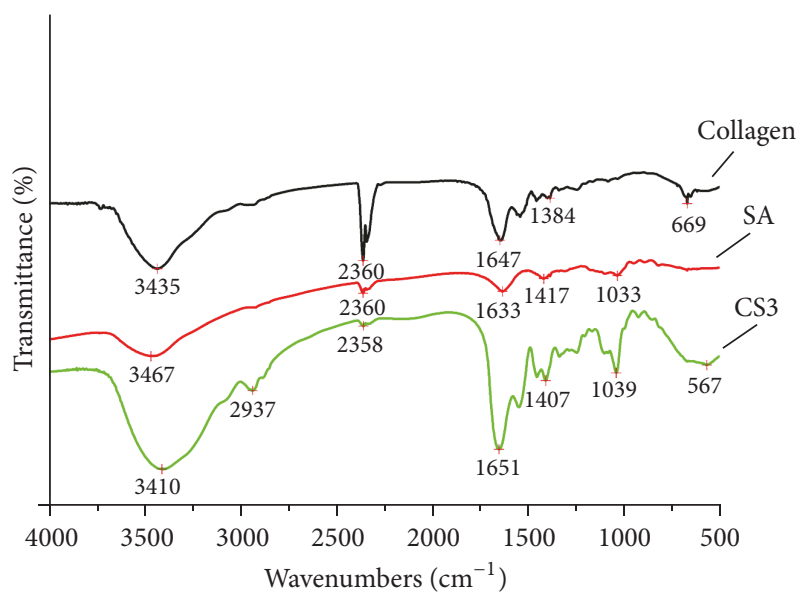

FIGURE 4: FTIR spectra of the different films (collagen, SA, and CS3) studied in all the range absorption.

\subsection{Microstructure Characterization}

3.3.1. FTIR. FTIR spectra of collagen, SA, and their blend films at selected concentrations were depicted in Figure 4. A robust classification of FTIR spectra collagen could be obtained by using a combination of four spectral intervals $\left[\nu(\mathrm{C}=\mathrm{O})\right.$ absorption of amide I $\left(1,700-1,600 \mathrm{~cm}^{-1}\right), \delta(\mathrm{CH} 2)$, and $\delta(\mathrm{CH} 3)$ absorptions $\left(1,480-1,350 \mathrm{~cm}^{-1}\right), \nu(\mathrm{C}-\mathrm{N})$, and $\delta(\mathrm{N}-\mathrm{H})$ absorptions of amide III $\left(1,300-1,180 \mathrm{~cm}^{-1}\right)$, and $(\mathrm{C}-\mathrm{O})$ and $(\mathrm{C}-\mathrm{O}-\mathrm{C})$ absorptions of carbohydrate moieties $\left(1,100-1,005 \mathrm{~cm}^{-1}\right)$ ] [51]. Both collagen and CS3 spectra showed similar IR absorbance patterns.

For CS3, the $\mathrm{OH}$ stretching and asymmetric $\mathrm{COO}$ stretching shift to a lower wavenumber (from 3435 to $3410 \mathrm{~cm}^{-1}$ ). Generally, the shift to the lower wavenumber indicated the existence of hydrogen bonds in collagen [50]. It also indicated that no other bonds except hydrogen bonds were formatted between collagen and SA.

3.3.2. SEM. Scanning electron microscopy (SEM) observations were carried out to get a better insight into the homogeneity and the microstructure of the blend films (Figure 5). SEM images of the surface of the collagen, SA, CS1, CS2, and CS3 films, and cross section of the CS2 films were presented. It was observed that collagen fiber was arranged in the film matrix, without pores and with excellent structural integrity (Figure 5(a)). SA exhibited rough surfaces with nonporous and heterogeneous morphologies due to some nonfully destructured alginate particles (Figure 5(b)). While more SA was added to the blend, the surface of CS2 and CS3 exhibited rougher and fluctuant matrix morphology (Figures 5(d) and 5(e)). Nevertheless, SEM images revealed that CS films had a smoother surface compared to pure SA films which became rougher upon drying. The cross section of CS2 had a compact and homogeneous structure and no distinct phase separation was observed (Figure 5(f)), indicating the integrity of the blend structure.

The above results lead to the following suggestions about the formation mechanism of the CS blend films. When SA were added to collagen films, the low molecular weight 


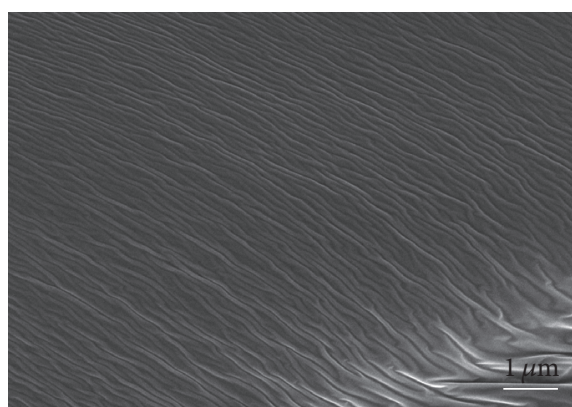

(a)

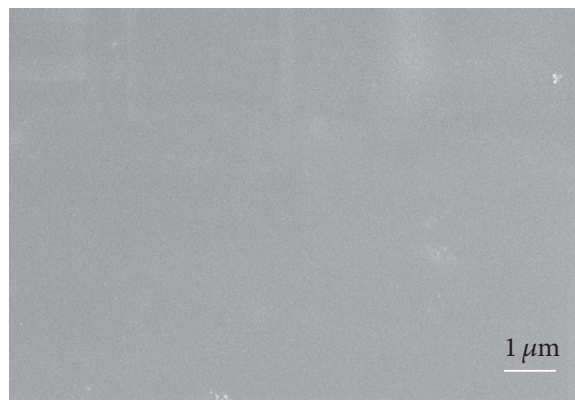

(c)

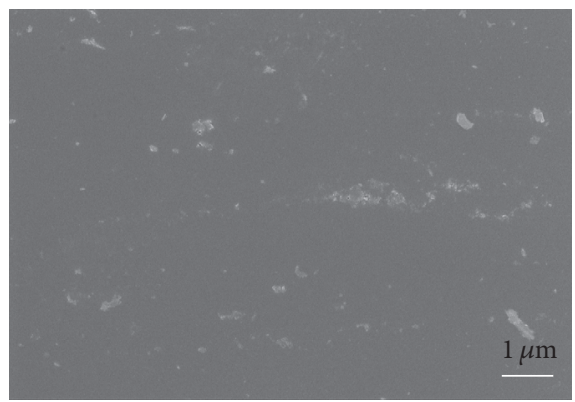

(e)

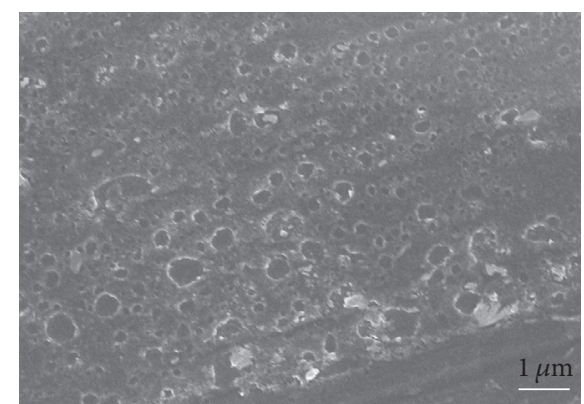

(b)

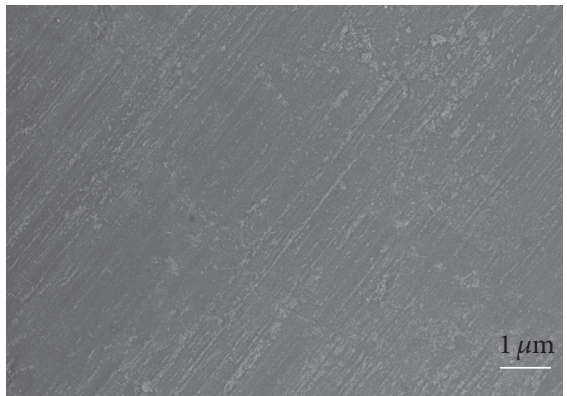

(d)

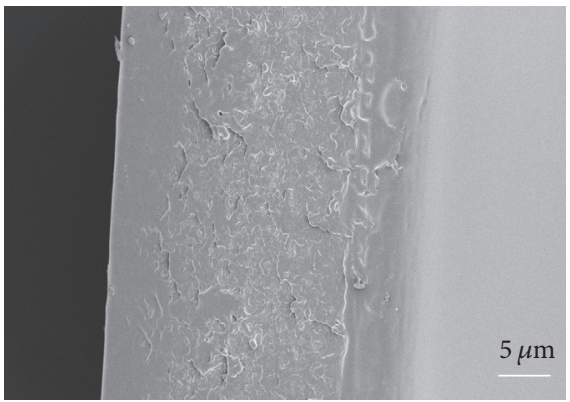

(f)

FIGURE 5: SEM micrographs of the surface of the films based on (a) the pure collagen film, (b) SA film, (c) CS1, (d) CS2, and (e) CS3. SEM micrographs of the cross section appearance of the films based on (f) CS2.

hydrophilic SA molecular movement was depressed by the formed strong cross-linking network structure, resulting in improved mechanical stability.

3.3.3. AFM. AFM images were obtained in order to provide the information of surface morphology and roughness for the sample film. Figure 6 shows surface morphologies and the corresponding results of roughness parameters $(R q$, root mean square of roughness, and $R a$, mean value of roughness) of the films. The surface morphology of SA film (Figure 6(a)) showed that bright protuberant parts were obviously observed due to SA molecule self-aggregation. Some significant differences between SA and CS films are exhibited. Obviously, the presence of collagen led to a marked decrease in the roughness of the films, as indicated by lower
$R a$ and $R q$ values. The results were accordant with the SEM microstructure observations.

\section{Conclusion}

Scale-up collagen/sodium alginate (CS) films were successfully prepared and their physical, mechanical, and barrier properties were evaluated. SEM and AFM analysis verified the homogeneity of the blend films while FTIR indicated hydrogen bonds formed between collagen and sodium alginate. Also, DSC suggested that their thermal stability has improved, owing to the addition of SA.

Furthermore, with increasing concentration of SA, TS increased and $E$ decreased while WVP initially decreased and then increased. Relatively, no obvious difference on OP for 


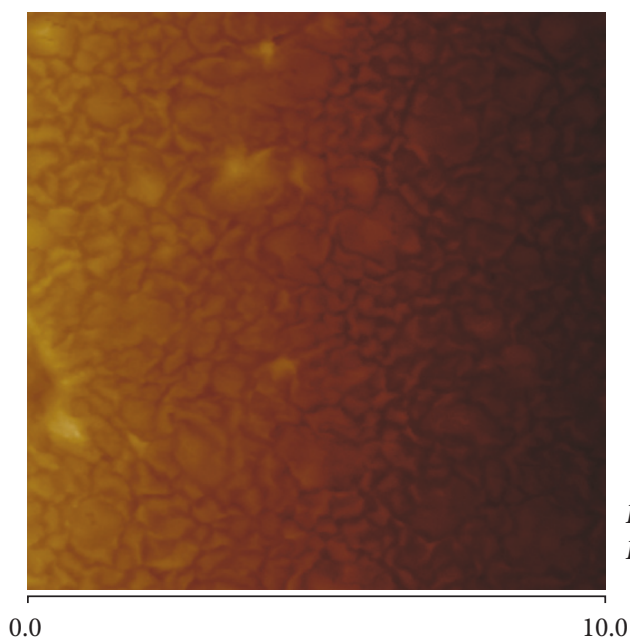

$(\mu \mathrm{m})$

(a)

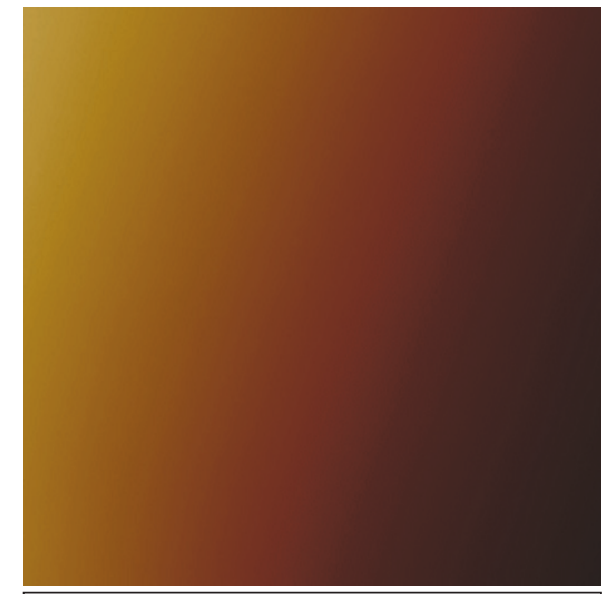

0.0

$(\mu \mathrm{m})$

(c)

10.0

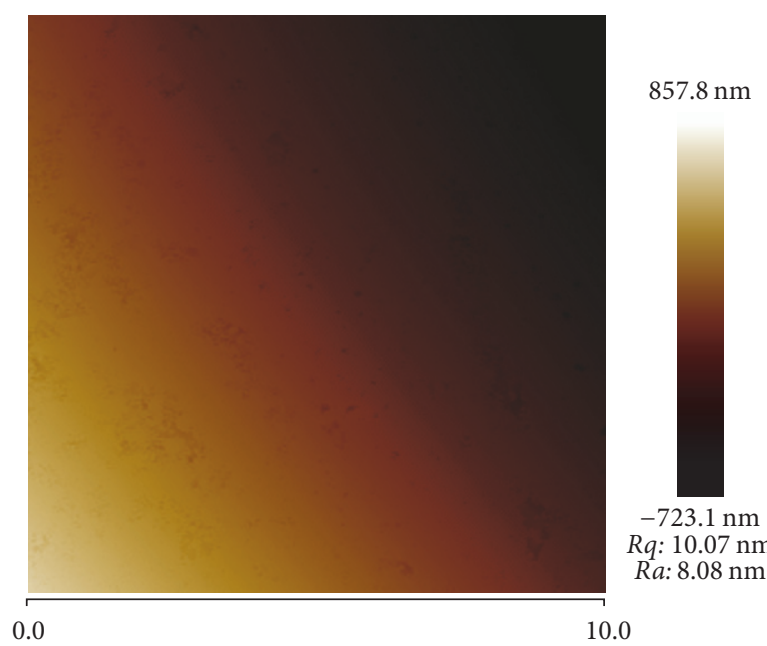

$(\mu \mathrm{m})$

(b)

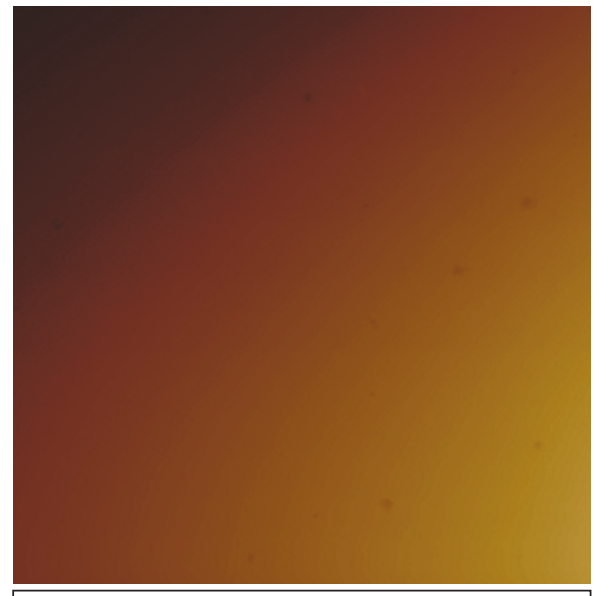

$693.5 \mathrm{~nm}$

$588.6 \mathrm{~nm}$

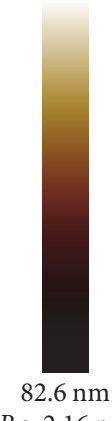

$R q: 2.16 \mathrm{~nm}$

$R a: 1.52 \mathrm{~nm}$

(d)

FIgURE 6: AFM images of the films: (a) SA film, (b) CS1, (c) CS2, and (d) CS3.

the CS films was obtained $(P>0.05)$. Results revealed that CS films with appropriate physical, mechanical, and barrier attributes could be effectively produced and successfully utilized in the food packaging industry.

\section{Conflicts of Interest}

The authors declare that the mentioned received funding in the Acknowledgments did not lead to any conflicts of interest regarding the publication of this manuscript.

\section{Acknowledgments}

This work was supported by Shenzhen Technology Research Project [JSGG2016022901849420], Shenzhen Overseas Special Fund for High-Level Talents [KQJSCX2017033116171850], and Guangdong Natural Science Foundation of China [2014A030310152].

\section{References}

[1] P. Cazón, G. Velazquez, J. A. Ramírez, and M. Vázquez, "Polysaccharide-based films and coatings for food packaging: A review," Food Hydrocolloids, vol. 68, pp. 136-148, 2017.

[2] M. de Morais Lima, D. Bianchini, A. Guerra Dias, E. da Rosa Zavareze, C. Prentice, and A. da Silveira Moreira, "Biodegradable films based on chitosan, xanthan gum, and fish protein hydrolysate," Journal of Applied Polymer Science, vol. 134, no. 23, Article ID 44899, 2017.

[3] A. Basu, S. Kundu, S. Sana et al., "Edible nano-bio-composite film cargo device for food packaging applications," Food Packaging and Shelf Life, vol. 11, pp. 98-105, 2017.

[4] T. J. Gutiérrez, J. Suniaga, A. Monsalve, and N. L. García, "Influence of beet flour on the relationship surface-properties of edible and intelligent films made from native and modified plantain flour," Food Hydrocolloids, vol. 54, pp. 234-244, 2016. 
[5] A. Manrich, F. K. V. Moreira, C. G. Otoni, M. V. Lorevice, M. A. Martins, and L. H. C. Mattoso, "Hydrophobic edible films made up of tomato cutin and pectin," Carbohydrate Polymers, vol. 164, pp. 83-91, 2017.

[6] B. Marcos, P. Gou, J. Arnau, and J. Comaposada, "Influence of processing conditions on the properties of alginate solutions and wet edible calcium alginate coatings," LWT-Food Science and Technology, vol. 74, pp. 271-279, 2016.

[7] Q. Xiao, L.-T. Lim, Y. Zhou, and Z. Zhao, "Drying process of pullulan edible films forming solutions studied by low-field NMR," Food Chemistry, vol. 230, pp. 611-617, 2017.

[8] M. de Morais Lima, L. C. Carneiro, D. Bianchini et al., "Structural, Thermal, Physical, Mechanical, and Barrier Properties of Chitosan Films with the Addition of Xanthan Gum," Journal of Food Science, vol. 82, no. 3, pp. 698-705, 2017.

[9] E. Oregel-Zamudio, M. V. Angoa-Pérez, G. Oyoque-Salcedo, C. N. Aguilar-González, and H. G. Mena-Violante, "Effect of candelilla wax edible coatings combined with biocontrol bacteria on strawberry quality during the shelf-life," Scientia Horticulturae, vol. 214, pp. 273-279, 2017.

[10] D. Peng, W. Jin, J. Li et al., "Adsorption and Distribution of Edible Gliadin Nanoparticles at the Air/Water Interface," Journal of Agricultural and Food Chemistry, vol. 65, no. 11, pp. 24542460, 2017.

[11] J. Hartman, A.-C. Albertsson, M. S. Lindblad, and J. Sjöberg, "Oxygen barrier materials from renewable sources: Material properties of softwood hemicellulose-based films," Journal of Applied Polymer Science, vol. 100, no. 4, pp. 2985-2991, 2006.

[12] Á. M. Lima, M. A. Cerqueira, B. W. S. Souza et al., "New edible coatings composed of galactomannans and collagen blends to improve the postharvest quality of fruits-influence on fruits gas transfer rate," Journal of Food Engineering, vol. 97, no. 1, pp. 101-109, 2010.

[13] H. M. C. Azeredo and K. W. Waldron, "Crosslinking in polysaccharide and protein films and coatings for food contact - A review," Trends in Food Science \& Technology, vol. 52, pp. 109$122,2016$.

[14] S. Singh, M. ho Lee, L. Park, Y. Shin, and Y. S. Lee, "Antimicrobial seafood packaging: a review," Journal of Food Science and Technology, vol. 53, no. 6, pp. 2505-2518, 2016.

[15] J. G. Borges, A. G. Silva, C. M. Cervi-Bitencourt, F. M. Vanin, and R. A. Carvalho, "Lecithin, gelatin and hydrolyzed collagen orally disintegrating films: Functional properties," International Journal of Biological Macromolecules, vol. 86, pp. 907-916, 2016.

[16] S. Chen, L. Tang, W. Su, W. Weng, K. Osako, and M. Tanaka, "Separation and characterization of alpha-chain subunits from tilapia (Tilapia zillii) skin gelatin using ultrafiltration," Food Chemistry, vol. 188, pp. 350-356, 2015.

[17] K. Wang, W. Wang, R. Ye et al., "Mechanical properties and solubility in water of corn starch-collagen composite films: Effect of starch type and concentrations," Food Chemistry, vol. 216, pp. 209-216, 2017.

[18] W. Wang, Y. Zhang, R. Ye, and W. Zhao, "Physicochemical characteristics and gelation properties of collagen superfine powder from swine skin: The effects of preheating treatment," International Journal of Food Science \& Technology, vol. 51, no. 5, pp. 1291-1297, 2016.

[19] Z. Wang, S. Hu, Y. Gao, C. Ye, and H. Wang, "Effect of collagenlysozyme coating on fresh-salmon fillets preservation," $L W T$ Food Science and Technology, vol. 75, pp. 59-64, 2017.

[20] X. Wu, Y. Liu, A. Liu, and W. Wang, "Improved thermal-stability and mechanical properties of type I collagen by crosslinking with casein, keratin and soy protein isolate using transglutaminase," International Journal of Biological Macromolecules, vol. 98, pp. 292-301, 2017.

[21] M. He, B. Zhang, Y. Dou, G. Yin, and Y. Cui, "Blend modification of feather keratin-based films using sodium alginate," Journal of Applied Polymer Science, vol. 134, no. 15, Article ID 44680, 2017.

[22] K. R. Aadil and H. Jha, "Physico-chemical properties of lignin-alginate based films in the presence of different plasticizers," Iranian Polymer Journal (English Edition), vol. 25, no. 8, pp. 661-670, 2016.

[23] Q. Ma, L. Du, Y. Yang, and L. Wang, "Rheology of film-forming solutions and physical properties of tara gum film reinforced with polyvinyl alcohol (PVA)," Food Hydrocolloids, vol. 63, pp. 677-684, 2017.

[24] S. A. Sumi, W. Rahman, J. Alam, N. C. Dafader, S. Manir, and M. R. Khan, "Irradiated sodium-alginate/poly(ethylene oxide) blend films improved by methyl acrylate monomer," Journal of Applied Polymer Science, vol. 133, no. 26, Article ID 43562, 2016.

[25] L. Zhang, S. Li, Y. Dong, H. Zhi, and W. Zong, “Tea polyphenols incorporated into alginate-based edible coating for quality maintenance of Chinese winter jujube under ambient temperature," LWT- Food Science and Technology, vol. 70, pp. 155-161, 2016.

[26] C. B. Amara, N. Eghbal, N. Oulahal, P. Degraeve, and A. Gharsallaoui, "Properties of lysozyme/sodium alginate complexes for the development of antimicrobial films," Food Research International, vol. 89, pp. 272-280, 2016.

[27] A. Bora and P. Mishra, "Characterization of casein and casein-silver conjugated nanoparticle containing multifunctional (pectin-sodium alginate/casein) bilayer film," Journal of Food Science and Technology, vol. 53, no. 10, pp. 3704-3714, 2016.

[28] Q. Xiao, Q. Tong, and L.-T. Lim, "Pullulan-sodium alginate based edible films: Rheological properties of film forming solutions," Carbohydrate Polymers, vol. 87, no. 2, pp. 1689-1695, 2012.

[29] C. M. Ortiz, J. O. de Moraes, A. R. Vicente, J. B. Laurindo, and A. N. Mauri, "Scale-up of the production of soy (Glycine max L.) protein films using tape casting: Formulation of film-forming suspension and drying conditions," Food Hydrocolloids, vol. 66, pp. 110-117, 2017.

[30] Z. Wang, X.-X. Sun, Z.-X. Lian, X.-X. Wang, J. Zhou, and Z.S. Ma, "The effects of ultrasonic/microwave assisted treatment on the properties of soy protein isolate/microcrystalline wheatbran cellulose film," Journal of Food Engineering, vol. 114, no. 2, pp. 183-191, 2013.

[31] C.-H. Chen, W.-S. Kuo, and L.-S. Lai, "Rheological and physical characterization of film-forming solutions and edible films from tapioca starch/decolorized hsian-tsao leaf gum," Food Hydrocolloids, vol. 23, no. 8, pp. 2132-2140, 2009.

[32] D. Peressini, B. Bravin, R. Lapasin, C. Rizzotti, and A. Sensidoni, "Starch-methylcellulose based edible films: rheological properties of film-forming dispersions," Journal of Food Engineering, vol. 59, no. 1, pp. 25-32, 2003.

[33] K. N. Turhan, F. Sahbaz, and A. Güner, "A spectrophotometric study of hydrogen bonding in methylcellulose-based edible films plasticized by polyethylene glycol," Journal of Food Science, vol. 66, no. 1, pp. 59-62, 2001.

[34] M. Maizura, A. Fazilah, M. H. Norziah, and A. A. Karim, "Antibacterial activity and mechanical properties of partially hydrolyzed sago starch-alginate edible film containing lemongrass oil," Journal of Food Science, vol. 72, no. 6, pp. C324-C330, 2007. 
[35] S. Galus and A. Lenart, "Development and characterization of composite edible films based on sodium alginate and pectin," Journal of Food Engineering, vol. 115, no. 4, pp. 459-465, 2013.

[36] S. C. Beristain-Bauza, E. Mani-López, E. Palou, and A. LópezMalo, "Antimicrobial activity and physical properties of protein films added with cell-free supernatant of Lactobacillus rhamnosus," Food Control, vol. 62, pp. 44-51, 2016.

[37] D. Clarke, A. A. Tyuftin, M. C. Cruz-Romero et al., "Surface attachment of active antimicrobial coatings onto conventional plastic-based laminates and performance assessment of these materials on the storage life of vacuum packaged beef subprimals," Food Microbiology, vol. 62, pp. 196-201, 2017.

[38] C. Schmitt, C. Sanchez, S. Desobry-Banon, and J. Hardy, "Structure and technofunctional properties of protein-polysaccharide complexes: A review," Critical Reviews in Food Science and Nutrition, vol. 38, no. 8, pp. 689-753, 1998.

[39] M. A. D. Silva, A. C. K. Bierhalz, and T. G. Kieckbusch, "Alginate and pectin composite films crosslinked with $\mathrm{Ca}^{2}+$ ions: Effect of the plasticizer concentration," Carbohydrate Polymers, vol. 77, no. 4, pp. 736-742, 2009.

[40] A. Nešić, A. Onjia, S. Davidović et al., "Design of pectin-sodium alginate based films for potential healthcare application: Study of chemico-physical interactions between the components of films and assessment of their antimicrobial activity," Carbohydrate Polymers, vol. 157, pp. 981-990, 2017.

[41] L. Wang, M. A. E. Auty, and J. P. Kerry, "Physical assessment of composite biodegradable films manufactured using whey protein isolate, gelatin and sodium alginate," Journal of Food Engineering, vol. 96, no. 2, pp. 199-207, 2010.

[42] J.-W. Rhim, "Physical and mechanical properties of water resistant sodium alginate films," LWT - Food Science and Technology, vol. 37, no. 3, pp. 323-330, 2004.

[43] G. Gautam and P. Mishra, "Development and characterization of copper nanocomposite containing bilayer film for coconut oil packaging," Journal of Food Processing and Preservation, 2017.

[44] A. Hambleton, A. Voilley, and F. Debeaufort, "Transport parameters for aroma compounds through i-carrageenan and sodium alginate-based edible films," Food Hydrocolloids, vol. 25, no. 5, pp. 1128-1133, 2011.

[45] A. Nawab, F. Alam, M. A. Haq, Z. Lutfi, and A. Hasnain, "Mango kernel starch-gum composite films: Physical, mechanical and barrier properties," International Journal of Biological Macromolecules, vol. 98, pp. 869-876, 2017.

[46] J. Bonilla, L. Atarés, M. Vargas, and A. Chiralt, "Edible films and coatings to prevent the detrimental effect of oxygen on food quality: Possibilities and limitations," Journal of Food Engineering, vol. 110, no. 2, pp. 208-213, 2012.

[47] M. Kumari, H. Mahajan, R. Joshi, and M. Gupta, "Development and structural characterization of edible films for improving fruit quality," Food Packaging and Shelf Life, vol. 12, pp. 42-50, 2017.

[48] M. M. Alves, M. P. Gonçalves, and C. M. R. Rocha, "Effect of ferulic acid on the performance of soy protein isolate-based edible coatings applied to fresh-cut apples," LWT- Food Science and Technology, vol. 80, pp. 409-415, 2017.

[49] S. Yoo and J. M. Krochta, "Whey protein-polysaccharide blended edible film formation and barrier, tensile, thermal and transparency properties," Journal of the Science of Food and Agriculture, vol. 91, no. 14, pp. 2628-2636, 2011.

[50] M. Ahmad, N. P. Nirmal, and J. Chuprom, "Molecular characteristics of collagen extracted from the starry triggerfish skin and its potential in the development of biodegradable packaging film," RSC Advances, vol. 6, no. 40, pp. 33868-33879, 2016.

[51] K. Belbachir, R. Noreen, G. Gouspillou, and C. Petibois, "Collagen types analysis and differentiation by FTIR spectroscopy," Analytical and Bioanalytical Chemistry, vol. 395, no. 3, pp. 829837, 2009. 

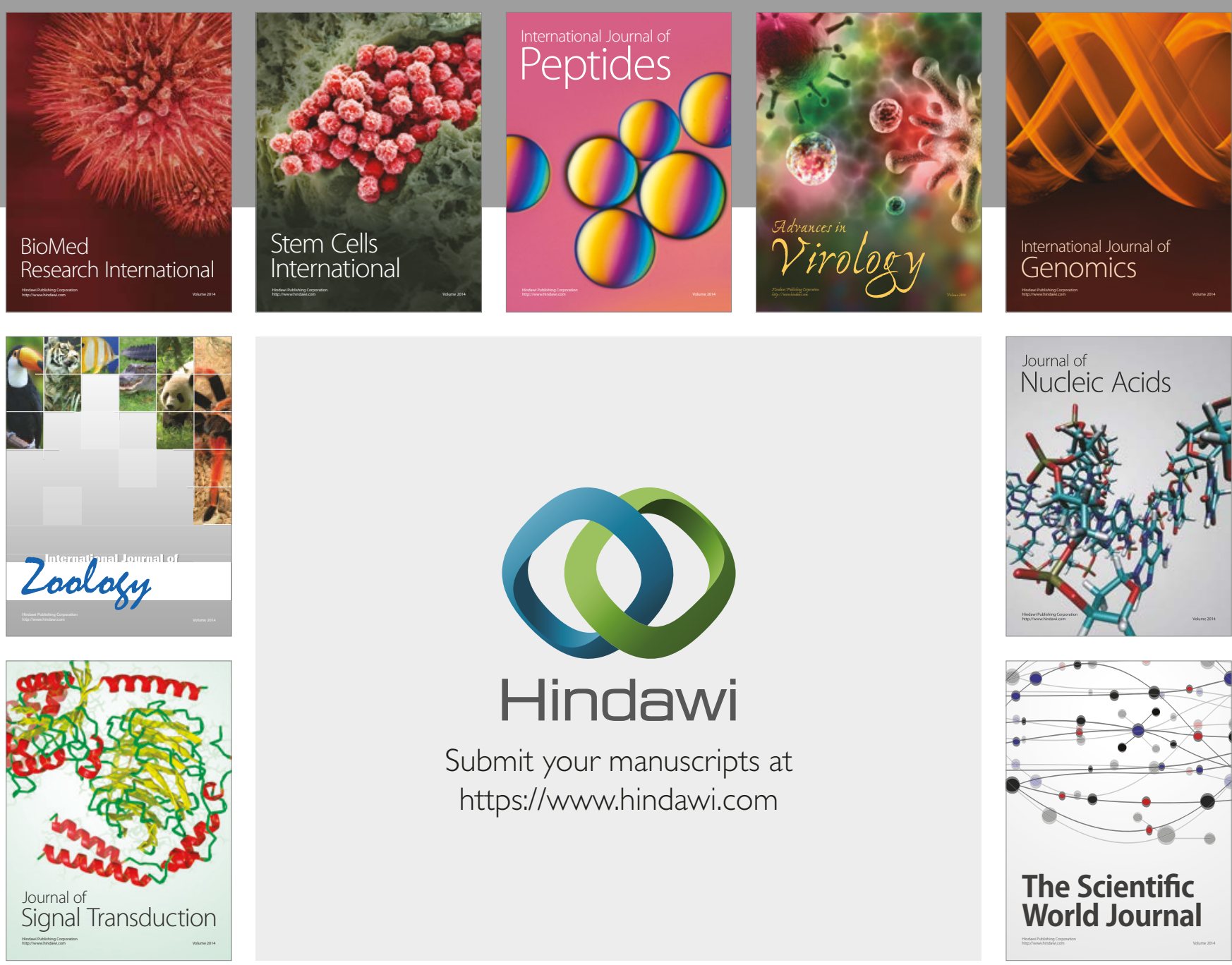

Submit your manuscripts at

https://www.hindawi.com
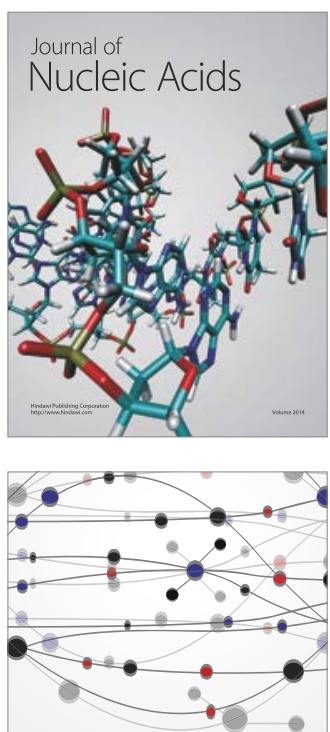

The Scientific World Journal

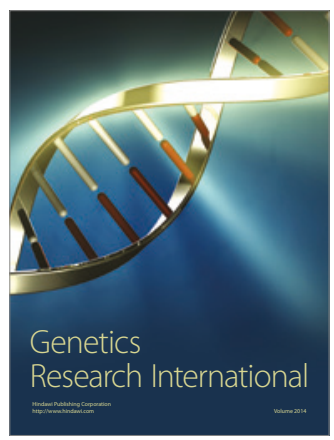

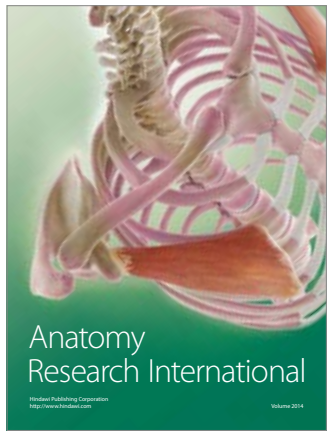

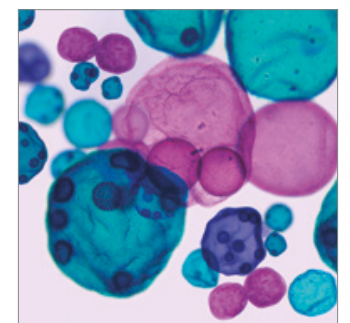

International Journal of Microbiology
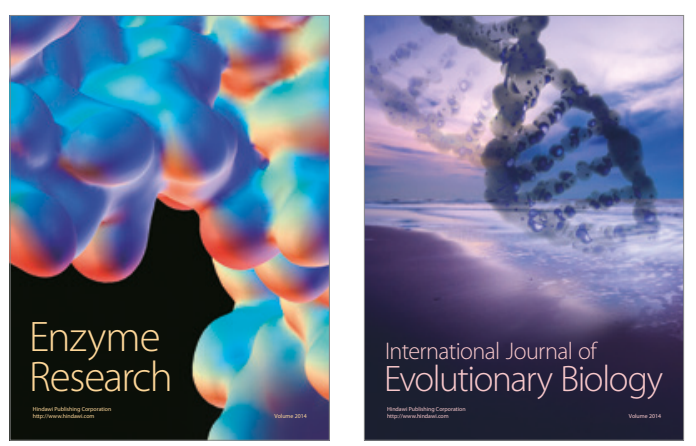
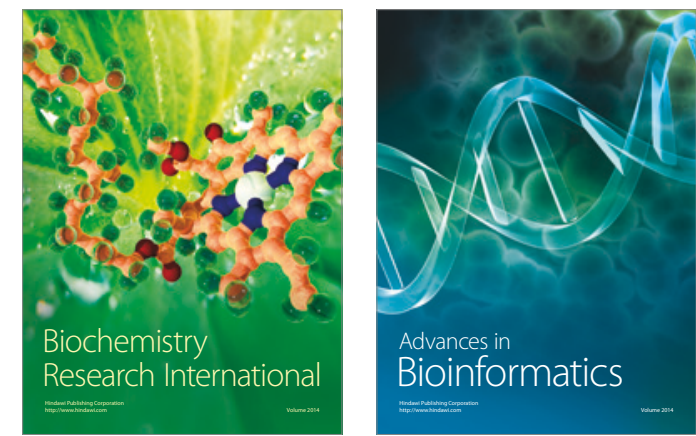

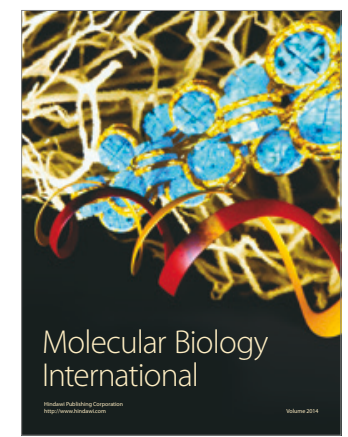

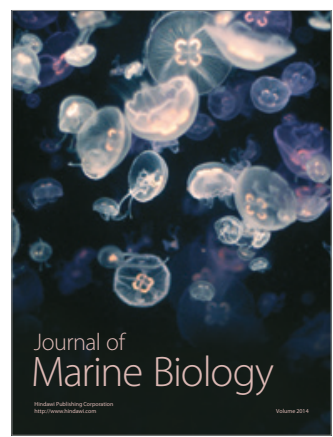

